\title{
芳香性稀土金属杂环丙烯化合物
}

\author{
王 凯 周锡庚* \\ (复旦大学化学系 上海 200433)
}

\section{Aromatic Scandacyclopropenes: Synthesis, Structure, and Reactivity}

\author{
Wang, Kai Zhou, Xigeng* \\ (Department of Chemistry, Fudan University, Shanghai 200433)
}

金属杂环丙烯因其独特的结构、反应性和广泛的应 用, 在金属有机化学中具有重要的地位. 过去四十多年 里, $d$-过渡、主族和钶系金属的杂环丙烯化合物得到了 广泛深入研究, 展示出了诱人的发展前景 ${ }^{[1 \sim 4]}$. 例如, 过渡金属杂环丙烯已成为设计众多过渡金属催化反应, 如炔烃羧基化反应等的关键中间体 ${ }^{[5]}$; 而基于芳香性杂 环并过渡金属杂环丙烯中间体的开环反应则为芳环碳碳键断裂提供了一种新方法 ${ }^{[6]}$. 此外, 炔烃形成金属杂 环丙烯反应还是一种保护炔的有效方法 ${ }^{[7]}$. 继续发展含 不同金属的杂环丙烯对深入了解这类化合物的成键性 质和内在反应性、拓展其应用至关重要, 因为改变金属 性质会对金属杂环丙烯配合物的成键性质和反应性产 生重要影响, 对开发新的炔烃还原偶联反应和设计新的 相关炔烃反应催化剂具有指导意义. 稀土是元素周期表 中最大的一个副族元素, 具有独特的电子结构和难以替 代的理化性质. 但值得注意的是, 稀土金属杂环丙烯化 合物的合成迄今几乎无人问津, 对于稀土金属杂环丙烯 是否具有芳香性还不得而知, 其反应化学研究更是一片 空白(图 1a $)^{[8]}$. 究其原因主要是稀土金属杂环丙烯化合 物的合成具有更大挑战性. 这主要源于两方面因素: 一 是与过渡金属和钣系金属不同, 大部分稀土金属只有单 一+3 价稳定氧化态, 难发生可逆的 2 电子氧化还原反 应, 现有的合成其它金属杂环丙烯的方法对稀土金属很 难适用. 二是大的金属离子半径和高的正电性决定了稀 土金属杂环丙烯化合物高度立体配位不饱和, 烯基双负 离子与稀土金属之间的结合力较弱, 化合物稳定性较 差, 难分离和结构表征. 与过渡金属类似化合物相比, 稀土元素强的路易斯酸时常能导致新的和有趣的反应 模式. 显然, 尽快填补稀土金属杂环丙烯方面的研究空
白, 对于丰富金属有机化学和发展金属杂环丙烯化 学而言, 是极其重要和高度期盼的.

北京大学化学学院席振峰和张文雄团队 ${ }^{[9]}$ 在前期研 究稀土金属䥻杂环伐二烯发生骨架重排构建双卡宾镜 配合物反应中, 创新性地提出该反应可能经历了尚未表 征的锌杂环丙烯中间体过程. 可喜的是, 通过双氯桥联 锌配合物与石墨钾和炔烃的 “一锅” 反应, 他们最近成 功地制备并分离了首个以盐型形式得以稳定的钪杂环 丙烯化合物(图 1b). 该钪杂环丙稀化合物的结构得到了 NMR 和 X 射线单晶衍射等表征. 同时, 密度泛函理论 (DFT)计算表明, 在该锁杂环丙稀结构单元中, $\mathrm{C}=\mathrm{C}$ 双 键中的 $\pi$ 电子一定程度上离域到整个 $\mathrm{Sc}-\mathrm{C}-\mathrm{C}$ 三元环 中心, 形成三中心-两电子的符合 Hückel $(4 n+2)$ 规则的 芳香体系. 定域化轨道定位函数(Localized orbital locator, LOL)图也清晰地表明了电子云在三中心的离域作 用, 该三元环的核独立化学位移 $\operatorname{NICS}(1)_{\mathrm{zz}}$ 的值为 $\delta-$ 10 , 进一步验证了该体系的芳香性特质(图 1c). 基于这 些分析，首次阐明了稀土金属杂环丙烯化合物具有芳香 性 ${ }^{[10]}$.

反应性研究结果显示, 这些张力钪杂环丙烯具有很 高的反应活性, 能与许多小分子发生反应, 并展现一些 与其它过渡金属杂环丙烯不同的反应特性(图 2). 例如, 可与三甲基硅基异氧酸酯(TMSNCO) 和笑气 $\left(\mathrm{N}_{2} \mathrm{O}\right)$ 发生 插入反应, 分别得到新颖的铅杂五元环和六元环化合 物; 可与三甲基硅基叠氮 $\left(\mathrm{TMSN}_{3}\right)$ 发生复分解反应, 形 成锌一双叠氮配合物; 能与二苯基连硫化合物和偶氮苯 发生氧化/还原反应, 释放出二苯乙炔, 并形成了相应的 苯基硫化合物或双负离子偶氮配位化合物等.

\footnotetext{
* Corresponding author. E-mail: xgzhou @ fudan.edu.cn. Published online March 20, 2020.
} 
(a)

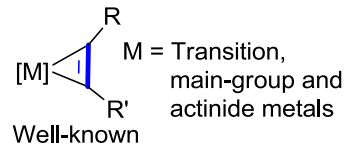

$[R E] \overbrace{R^{\prime}}^{R} \begin{aligned} & R E=\text { Rare-earth } \\ & \text { metals }\end{aligned}$

Still Challenging (b) Synthesis

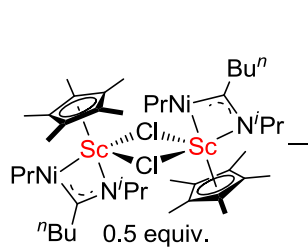

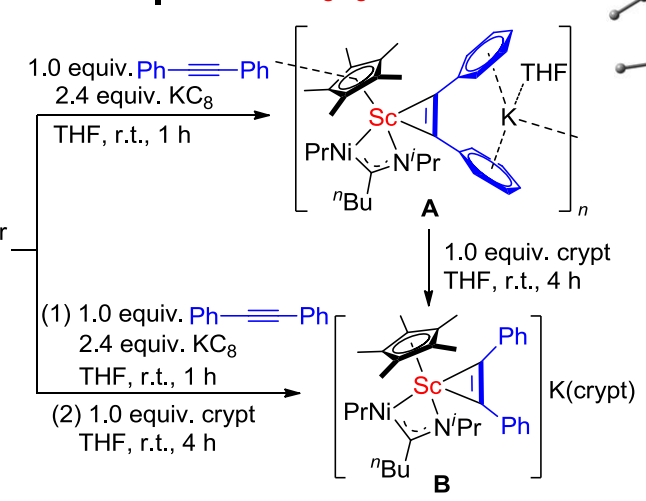

(c) Aromaticity

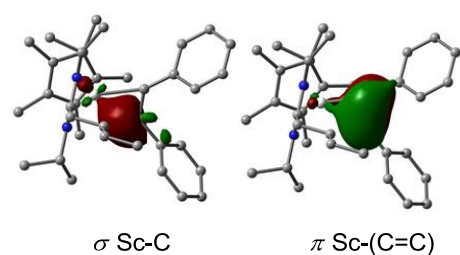

The localized molecular orbitals

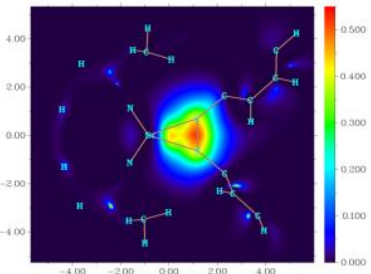

LOL color-filled map

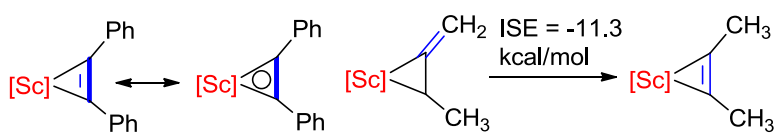

Two resonance structures

图 1 钪杂环丙烯的合成和结构表征

Figure 1 Synthesis and structural characterization of scandacyclopropenes

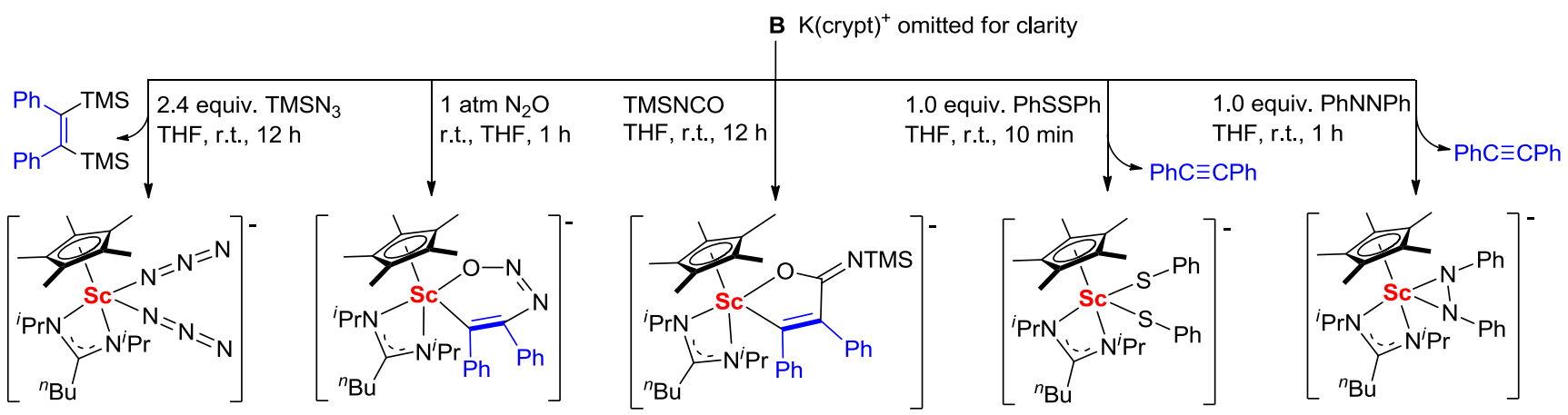

图 2 化合物 $\mathbf{B}$ 与不同基质的反应性研究

Figure 2 Reactivity of complex $\mathbf{B}$ toward various substrates

席振峰和张文雄等报道的锫杂环丙烯化合物的合 成及其环结构的芳香性发现, 使人们对稀土金属化合物 的成键性质及反应特性有了新认识. 这有助于引领人们 进入尚未开发的稀土化学空间. 此外, 他们利用阴离子 金属中心周围额外配体的立体和电子效应, 缓解稀土杂 环丙烯的高正电性和配位不饱和的策略, 为其它新颖稀 土金属化合物的设计合成及反应性研究, 特别是如何稳 定高活性稀土物种, 提供了新思路和新借鉴.

另一方面, 作为特定的反应物, 炔烃在有机合成中 的应用很大程度上依赖于其活性中间体的形成. 因此, 发展多用途的炔烃交叉还原偶联方法是金属有机化学 和有机合成化学研究的一个重要课题. 尽管过渡金属在 导向炔烃转化方面已经被大量事实证明非常有效, 但是 它们并不能完全满足有机合成日益增长的需要, 如炔烃 与吩嗪的还原偶联还是一个基本挑战. 值得期待的是,
对难以捉摸的稀土金属杂环丙烯的独特反应性观察，也 有望激发对炔烃还原偶联反应化学的新探索.

\section{References}

[1] Zhu, H.; Oswald, R. B.; Fan, H.; Roesky, H. W.; Ma, Q.; Yang, Z.; Schmidt, H.-G.; Noltemeyer, M.; Starke, K.; Hosmane, N. S. J. Am. Chem. Soc. 2006, 128, 5100.

[2] Parker, K. D. J.; Fryzuk, M. D. Organometallics 2015, 34, 2037.

[3] Zi, G. Chem. Commun. 2018, 54, 7412.

[4] Rosenthal, U. Eur. J. Inorg. Chem. 2019, 2019, 895.

[5] Li, S.; Yuan, W.; Ma, S. Angew. Chem., Int. Ed. 2011, 50, 2578.

[6] Sattler, A.; Parkin, G. Nature 2010, 463, 523.

[7] Lai, T. Y.; Gullett, K. L.; Chen, C.-Y.; Fettinger, J. C.; Power, P. P. Organometallics 2019, 38, 1421.

[8] Hong, J. Q.; Li, Z. H.; Chen, Z. E.; Weng, L. H.; Zhou, X. G. Zhang, L. X. Dalton Trans. 2016, 45, 6641

[9] Ma, W.; Yu, C.; Chi, Y.; Chen, T.; Wang, L.; Yin, J.; Wei, B.; Xu, L.; Zhang, W.-X.; Xi, Z. Chem. Sci. 2017, 8, 6852.

[10] Lv, A.-J.; Huang, Z.; She, J.; Zhang, W.-X.; Xi, Z. J. Am. Chem. Soc. 2019, 141, 20547. 